\title{
Signatures of the 2-day wave and sudden stratospheric warmings in Arctic water vapour observed by ground-based microwave radiometry
}

\author{
B. Tschanz ${ }^{1,2}$ and N. Kämpfer ${ }^{1,2}$ \\ ${ }^{1}$ Institute of Applied Physics, University of Bern, Bern, Switzerland \\ ${ }^{2}$ Oeschger Center for Climate Change Research, University of Bern, Bern, Switzerland
}

Correspondence to: B. Tschanz (brigitte.tschanz@iap.unibe.ch)

Received: 3 November 2014 - Published in Atmos. Chem. Phys. Discuss.: 7 January 2015

Revised: 8 April 2015 - Accepted: 10 April 2015 - Published: 5 May 2015

\begin{abstract}
The ground-based microwave radiometer MIAWARA-C recorded the upper stratospheric and lower mesospheric water vapour distribution continuously from June 2011 to March 2013 above the Arctic station of Sodankylä, Finland $\left(67.4^{\circ} \mathrm{N}, 26.6^{\circ} \mathrm{E}\right)$ without major interruptions and offers water vapour profiles with temporal resolution of $1 \mathrm{~h}$ for average conditions. The water vapour time series of MIAWARA-C shows strong periodic variations in both summer and winter related to the quasi-2-day wave. Above $0.1 \mathrm{hPa}$ the amplitudes are strongest in summer. The stratospheric wintertime 2-day wave is pronounced for both winters on altitudes below $0.1 \mathrm{hPa}$ and reaches a maximum amplitude of $0.8 \mathrm{ppmv}$ in November 2011. Over the measurement period, the instrument monitored the changes in water vapour linked to two sudden stratospheric warmings in early 2012 and 2013. Based on the water vapour measurements, the descent rate in the vortex after the warmings is $364 \mathrm{~m} \mathrm{~d}^{-1}$ for 2012 and $315 \mathrm{~m} \mathrm{~d}^{-1}$ for 2013.
\end{abstract}

\section{Introduction}

The Arctic atmosphere is highly variable. Over the year, it is affected by the extremes of solar radiation ranging from long daylight periods in summer to the complete lack of Sun light in winter. The absence of radiative heating in the stratosphere leads to strong eastward winds, the polar vortex, and descent of air over the Arctic region in winter. As a consequence of the polar winter condition, the temperature of the stratosphere decreases allowing polar stratospheric clouds to form. These clouds play a major role in the heterogeneous catalytic destruction of ozone in spring. In addition to influencing the temperatures the polar vortex acts as a mixing barrier for trace gases. This mixing barrier can give rise to sharp gradients in trace gases such as nitrous oxide, ozone or water vapour.

Thanks to its relatively long chemical lifetime in the order of months in the stratosphere and weeks in the mesosphere (Brasseur et al., 1999), water vapour can be used as a tracer for dynamical events in the middle atmosphere wherever there are horizontal or vertical gradients in the water vapour distribution. The global mean circulation leads to horizontal water vapour gradients from polar to mid-latitudinal middle atmosphere. Therefore, monitoring water vapour in polar regions is valuable for monitoring dynamics and events such as sudden stratospheric warmings (SSWs). For recent studies using water vapour as a tracer see e.g. Lossow et al. (2009), Lee et al. (2011), Straub et al. (2012) and Scheiben et al. (2012). Ground-based microwave radiometry is the only method capable of obtaining middle atmospheric water vapour time series with temporal resolution of the order of an hour and therefore well suited for the investigation of dynamical effects in polar regions. The instruments measure reliably and can easily be maintained.

There are two major sources of middle atmospheric water vapour. The first one is vertical transport through the tropical transition layer. The lower stratosphere is extremely dry because of the cold tropopause temperatures in the Tropics resulting in freeze-drying. The second source of middle atmospheric water vapour is the oxidation of methane lead- 
ing to a positive vertical gradient in volume mixing ratio (VMR) throughout the stratosphere. The increasing photodissociation with altitude results in a negative gradient in the mesosphere.

The latitudinal distribution of water vapour in the middle atmosphere is mainly determined by the large-scale residual circulation. Above the winter polar region dry mesospheric air descends inducing horizontal gradients in the water vapour VMR, which are sustained by the vortex edge. These horizontal gradients make water vapour a valuable tracer for short-term transport in the winter hemisphere, e.g. in the course of SSW. Above the summer polar region, upwelling of relatively humid stratospheric air results in high water vapour VMR in the mesosphere.

Sudden stratospheric warmings are events occurring in the winter hemisphere and are characterised by a fast and strong increase of stratospheric temperature and simultaneous cooling of the mesosphere in the polar region. In the course of SSWs the polar circulation is strongly distorted from normal winter conditions with stratospheric zonal winds reversing to westward and the temperature increases from $60^{\circ} \mathrm{N}$ towards the pole. Studies of recent SSWs revealed transport processes and effects on tracers (Coy et al., 2009; Funke et al., 2010; Manney et al., 2009; Straub et al., 2012; Scheiben et al., 2012). The change in the wind field results in weakened or dissolved high-latitude transport barriers and leads to transport and mixing of air masses from lower latitudes to polar regions.

Uneven in situ heating of the atmosphere and the asymmetric distribution of land can excite planetary waves. $\mathrm{Nu}-$ merous studies identified the most prominent periods of these waves to be approximately 2 days, 5 days, 10 days and 16 days. The most prominent planetary wave component in the mesosphere is the quasi-2-day wave (Q2DW) with amplitudes larger than $10 \mathrm{~K}$ in temperature and wind amplitudes of several tens of $\mathrm{m} \mathrm{s}^{-1}$ in the mid- to low-latitude summer mesosphere (Tunbridge et al., 2011; Wu et al., 1993). The QT2W can interact with atmospheric tides and influence the variability of polar mesospheric clouds (Merkel et al., 2009; Kulikov, 2007). Most observational studies of the Q2DW focus on the summertime Q2DW with the largest amplitudes coming from westward propagating zonal wave numbers W2, W3 and W4 (e.g. Limpasuvan et al., 2000). In addition to analysis of dynamical variables, Limpasuvan and $\mathrm{Wu}$ (2003) analysed the summertime Q2DW in mesospheric water vapour measured by UARS MLS and found amplitudes of up to $0.35 \mathrm{ppmv}$ near the mesopause.

Recent studies discussed a strong Q2DW activity around winter solstice at high latitudes (Nozawa et al., 2003; Sandford et al., 2008; Tunbridge and Mitchell, 2009) related to an eastward-propagating E2 wave using wind measurements from meteor radars and geopotential height from Aura MLS.

Measurements of the state of the atmosphere are essential for increasing the understanding of the dynamically variable Arctic winter atmosphere and help to improve the qual- ity of models. Examples of recent studies using SSW events for comparing models and measurements are given in Salmi et al. (2011), Dörnbrack et al. (2012) and Pedatella et al. (2014). In addition to satellites, ground-based instruments are used to monitor the atmosphere. They offer the benefit of being relatively easy to maintain and of a long lifetime compared to satellite instruments. In this paper water vapour data obtained with a microwave radiometer at the Arctic station of the Finnish Meteorological Institute FMI in Sodankylä in Northern Finland is used to demonstrate the capability of ground-based measurements at one station to monitor variations caused by Q2DW and SSWs.

The ground-based Middle Atmospheric WAter vapour RAdiometer for Campaigns (MIAWARA-C) measured in Sodankylä for 20 months from June 2011 to March 2013. The high temporal resolution of the order of $1 \mathrm{~h}$ above one location can only be obtained by ground-based microwave radiometry. In addition, microwave radiometry is the only remote sensing technique capable of monitoring water vapour in the middle atmosphere from the ground (Kämpfer et al., 2012). Analysing the dominant periods in the water vapour variations on each altitude level, a strong Q2DW is identified and discussed. The wintertime Q2DW observed with MIAWARA-C is the first observation using ground-based microwave radiometry. The water vapour evolution was recorded without major interruptions and shows the effects on water vapour during two autumn descents, one spring ascent and two SSWs. In both winters, there has been a SSW. The 2012 and the 2013 SSWs are compared to the 2010 event which has been monitored by MIAWARA-C from the same location and is discussed in detail in Straub et al. (2012). Straub et al. (2012) found a descent rate after the SSW of $350 \pm 40 \mathrm{~m} \mathrm{~d}^{-1}$ by fitting the 5.2 ppmv isopleth. By using backward trajectory calculations, the observed increase in water vapour VMR between 0.1 and $0.03 \mathrm{hPa}$ could be attributed to meridional advection of subtropical air and mesospheric upwelling in the course of the SSW.

After describing the instrument, the measured water vapour time series is presented. The measured water vapour data are spectrally analysed and signatures of the summertime and wintertime Q2DW are discussed. Additionally, the two SSWs of 2012 and 2013 are discussed complementing the measured water vapour profiles with temperature data from Aura MLS and ECMWF model data.

\section{MIAWARA-C}

MIAWARA-C is a compact microwave radiometer designed for campaigns to measure middle-atmospheric water vapour profiles. It is controlled remotely and operated continuously under all weather conditions except rain. The pressure broadened emission line of water vapour at $22.235 \mathrm{GHz}$ is measured with a heterodyne receiver and spectrally analysed with a fast Fourier transform spectrometer and a spec- 
tral resolution of $30.5 \mathrm{kHz}$ and a usable spectral bandwidth of $400 \mathrm{MHz}$. A detailed description of the instrument is presented in Straub et al. (2010). With the ARTS/Qpack software package a water vapour profile is retrieved from the measured spectrum (Buehler et al., 2005; Eriksson et al., 2011) by the so-called optimal estimation technique (Rodgers, 2000). The retrieval version v1.1 used in this paper is described and validated in Tschanz et al. (2013).

For MIAWARA-C the reliable altitude range of the retrieval v1.1 is defined as the region where the area of the averaging kernel (AoA) is larger than 0.8. This definition results in a sensitive altitude range from $4 \mathrm{hPa}(37 \mathrm{~km})$ to $0.017 \mathrm{hPa}$ $(75 \mathrm{~km})$. Beyond these limits the instrument is still sensitive, however the contribution from the a priori profile increases and the quality of the assignment to altitude levels decreases. The full width at half maximum of the averaging kernels is a measure for the vertical resolution of the water vapour profiles and is approximately $12 \mathrm{~km}$ in the reliable altitude range. The measured and calibrated spectra are integrated prior to the retrieval in order to increase the signal-to-noise ratio. For v1.1 the spectra are integrated until they reach a fixed noise level which results in a constant altitude range and in a varying integration time. The number of retrieved profiles per day is mainly determined by the tropospheric conditions and is presented in Tschanz et al. (2013) for both the 2010 and the 2011-2013 campaigns in Sodankylä. On $60 \%$ of all measurement days during the 2011-2013 campaign 10 or more profiles per day can be retrieved from MIAWARA-C's measured spectra.

\section{Campaign overview}

MIAWARA-C monitored middle-atmospheric water vapour above Sodankylä over 20 months without major data gaps from 13 June 2011 until 7 March 2013. There are only three measurement gaps of more than $24 \mathrm{~h}$ over the whole measurement period. The interruptions are mainly caused by rain. With a constant noise level in brightness temperature of $0.0141 \mathrm{~K}$, a total of 8823 profiles could be retrieved.

An overview of the time series is presented in Fig. 1. The measurements of MIAWARA-C started in boreal summer with upwelling of humid stratospheric air into the mesosphere resulting in high water vapour VMR in the mesosphere. In September, the global circulation starts to turn to winter conditions with descent of dry mesospheric air shifting the water vapour maximum down to $10 \mathrm{hPa}$ which is around MIAWARA-C's lower altitude limit. As a result of the descent, the polar mesosphere is extremely dry.

The data set obtained by MIAWARA-C is ideally suited to investigate the temporal variability in water vapour caused by periodic phenomena on short timescales or effects of events such as SSWs. Investigation of the quasi-16-day wave in mesospheric water vapour during the boreal winter 2011/12 based on data from MIAWARA-C has already been pre- sented in Scheiben et al. (2014). This paper focuses on the effect of SSWs and the Q2DW.

In MIAWARA-C's time series the effects of two SSWs on water vapour are clearly visible, the first one taking place in January 2012 and the second one in January 2013. The central dates of the SSWs defined as the occurrence of the maximum zonal mean temperature at $1 \mathrm{hPa}$ and $60^{\circ} \mathrm{N}$ are marked as black dashed lines in Fig. 1. A detailed discussion of the influence of SSWs on middle atmospheric water vapour and the 2010 event as observed by MIAWARA-C are presented in Straub et al. (2012) and Scheiben et al. (2012). In the course of a SSW, the eastward winds in the stratosphere are reversed to westward and humid mid-latitudinal or subtropical air is transported into the Arctic region. MIAWARA-C observes this humid air as a sharp increase in water vapour from 2 to $0.1 \mathrm{hPa}$. After both SSWs, the circulation returns to normal winter conditions and the descent over the Arctic restarts, which can be seen as down-welling of water vapour in the time series. Details of the effects of the SSWs are discussed in Sect. 3.2.

In addition to the two reversals to winter conditions and the two SSWs, MIAWARA-C observed the change from winter to summer circulation in 2012 .

\subsection{Signatures of the quasi-2-day wave}

Ground-based microwave instruments for water vapour such as MIAWARA-C can achieve a high temporal resolution in the order of hours and offer the possibility to investigate short-term variations in the amount of the trace gas. The median of the integration time over the whole measurement period from June 2011 to March 2013 is below $1 \mathrm{~h}$ allowing the investigation of periodic structures in water vapour in an ideal way. Spectral decomposition of MIAWARA-C's time series showed dominant variations with periods of approximately 16, 10, 5 and 2 days. A detailed analysis of the evolution and regional differences of the quasi-16-day wave for winter 2011/12 has already been presented in Scheiben et al. (2014) using ground-based microwave data of trace gases including the data obtained with MIAWARA-C. In this study we concentrate on the investigation of the Q2DW. At mid-latitudes, the Q2DW is most pronounced in the summer mesosphere and only at high latitudes has the Q2DW been observed near winter solstice (Nozawa et al., 2003; Sandford et al., 2008; Tunbridge and Mitchell, 2009).

For the spectral decomposition a wavelet-like approach is chosen as described in Studer et al. (2012). We successfully applied this method to other middle atmospheric trace gas studies (e.g. Hocke et al., 2013; Scheiben et al., 2014). The wavelet-like analysis has the advantage of capturing variations with non-persistent phase. The data on each retrieval pressure level are treated as a separate time series. A digital non-recursive, zero-phase finite impulse response filter is applied using a Hamming window with a length of 3 times 


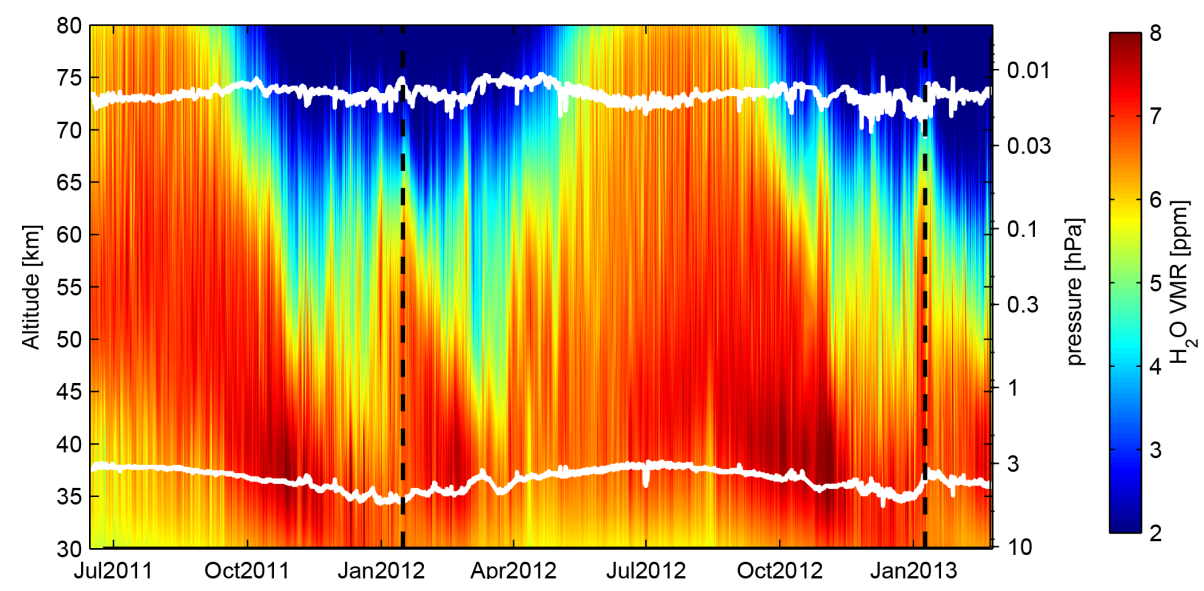

Figure 1. Overview of the water vapour time series measured by MIAWARA-C. The two black dashed lines mark the central dates of the two SSWs. The reliable altitude range is indicated by white lines $($ AoA $>0.8)$.

the centre period. We define the amplitude of the wave as peak-to-peak of the filtered signal.

The 2-day amplitude analysis of our data set is presented in Fig. 2. Generally, the Q2DW activity is stronger in the mesosphere above $0.1 \mathrm{hPa}$ than below and varies strongly with time with slightly higher values in late summer and autumn. July 2012 shows a strong and persisting Q2DW above $0.1 \mathrm{hPa}$. As an example of the 2-day amplitude in the mesosphere, the results on $0.05 \mathrm{hPa}$ are shown in detail in Figs. 4 and 5. Below $0.1 \mathrm{hPa}$ the amplitude is higher in winter than in summer and coincides with the presence of the polar vortex over Sodankylä from November to April. The strongest Q2DW effects are observed in November 2011; the activity is strongly increased, reaching values of up to $0.8 \mathrm{ppmv}$ from 0.8 to $0.1 \mathrm{hPa}$ corresponding to a relative amplitude of 10 $15 \%$.

A periodogram for the two periods with enhanced Q2DW activity is presented in Fig. 3 for two altitude levels, one above and one below $0.1 \mathrm{hPa}$. The amplitude shown is a mean value from 1 to 30 November 2011 and from 27 June to 24 July respectively. In November 2011, the 2-day wave is only observed on $1 \mathrm{hPa}$ but not in the mesosphere on $0.05 \mathrm{hPa}$. On the other hand, the example of a summer Q2DW for July 2012 shows enhanced activity above $0.1 \mathrm{hPa}$ but none on the lower stratospheric level. In addition to 2day activities, variations with periods from 14 to 18 days are visible on both altitude levels. In July 2012 on $0.05 \mathrm{hPa}$ in the mesosphere, a relatively strong variation with a period of approximately 5 days is observed. In middle to high latitudes the summertime quasi-5-day variation has been identified as being predominantly a planetary normal mode $(1,1)$ of Rossby waves (Merkel et al., 2003; Sonnemann et al., 2008). Sonnemann et al. (2008) have observed and analysed the quasi-5-day variations in a mesospheric water vapour data set obtained with a ground-based $22 \mathrm{GHz}$ microwave radiometer.
An illustration of the Q2DW for the two periods showing both filtered time series and measurement is given in Figs. 4 and 5. In order to enhance the visibility of the periodic 2day structure in the measurements, the filtered signals with periods of 5, 10 and 16 days are subtracted from the interpolated measurement. The mean of the measurement is added to the filtered signal. The close agreement of measurement and Q2DW signal on $1 \mathrm{hPa}$ shown in Fig. 4 suggests the conclusion that the Q2DW activity in November 2011 accounts for most of the remaining variation. The mesosphere does not show a strong correlation between measurement and filtered signal. For the summertime Q2DW, which is illustrated in Fig. 5, the remaining variations in the measured data agree well with the filtered signal in the mesosphere but not in the stratosphere.

\subsection{Signatures of 2012 and $2013 \mathrm{SSWs}$ in water vapour}

MIAWARA-C has monitored the water vapour evolution above Sodankylä during three SSWs in 2010, 2012 and 2013. The 2010 event is discussed thoroughly in Straub et al. (2012) and the discussion of the observed water vapour variations related to the following SSWs follows Straub et al. (2012). An overview of the 2012 and 2013 events is illustrated in Figs. 6 and 7 with water vapour measured by MIAWARA-C, zonal mean temperature from Aura MLS v2.2 at $80^{\circ} \mathrm{N}$ and operational ECMWF zonal mean zonal wind at $60^{\circ} \mathrm{N}$. The central date of the SSWs, which we define as the maximum zonal mean temperature at $1 \mathrm{hPa}$ and $60^{\circ} \mathrm{N}$, is 16 January for 2012 and 9 January for 2013 .

The 2012 event shows two maxima in temperature at $1 \mathrm{hPa}$ with the second one coinciding with the wind reversal. Trajectory analysis of the origin of the air above Sodankylä shows that both maxima coincide with transport from mid-latitudinal air (not shown here). The effects on water vapour can be seen for both temperature maxima as an increase between 1 and $0.03 \mathrm{hPa}$ caused by the transport of 


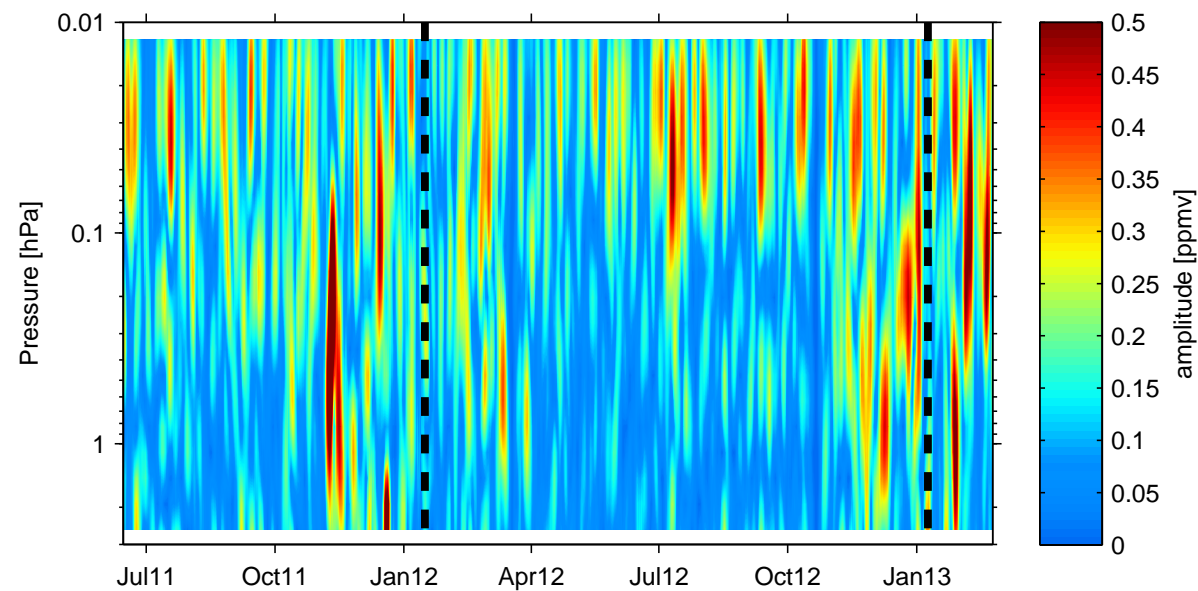

Figure 2. Amplitude of the 2-day activity in MIAWARA-Cs water vapour time series. The two black dashed lines mark the central dates of the two SSWs.
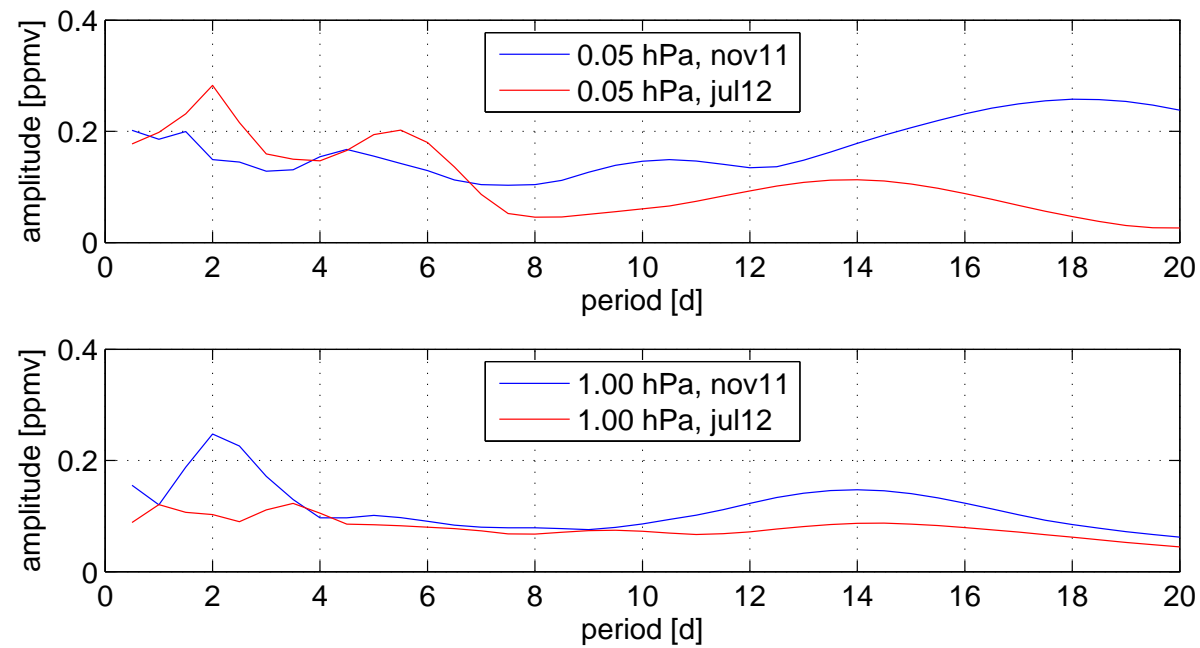

Figure 3. Mean amplitude of different periods obtained by filtering the water vapour time series on two altitude levels (top: $0.05 \mathrm{hPa}$, bottom: $1 \mathrm{hPa}$ ) for 1 to 30 November 2011 (blue) and 27 June to 24 July 2012 (red).

humid mid-latitudinal air into the polar region. The evolution of $80^{\circ} \mathrm{N}$ zonal mean temperature for 2012 is similar to 2010 (see Straub et al., 2012): at $1 \mathrm{hPa}$ the temperature increases by 20 and $30 \mathrm{~K}$ for 2010 and 2012 respectively whereas there is an increase of $50 \mathrm{~K}$ in 2013 . The 2013 event is characterised by extremely low temperatures of less than $200 \mathrm{~K}$ at approximately $3 \mathrm{hPa} 1$ month after the SSW. The wind reversal of 2013 reaches low stratospheric altitudes and persists in the lower stratosphere for more than 2 months.

The zonal mean water vapour distribution is determined by the general circulation. The descent above polar regions results in horizontal gradients of water vapour at the vortex edge. Inside the vortex, stratospheric air below $40-45 \mathrm{~km}$ is more humid than outside whereas the mesospheric vortex air is characterised as being drier than non-vortex air (Nassar et al., 2005; Lossow et al., 2009). As discussed in Scheiben et al. (2012), potential vorticity might be used as a tracer for vortex air in the lower stratosphere but does not correlate with the observed tracer distributions in the upper stratosphere and lower mesosphere. Therefore, we apply the distance to the vortex method described in Scheiben et al. (2012) as an indicator for vortex air. Negative distance to the vortex edge implies that the vortex is located above the station.

The water vapour measurements for the 2012 and the 2013 SSWs as well as the distance to the vortex edge above Sodankylä are shown in Figs. 6 and 7. Before the warmings the vortex is mainly centred at the pole resulting in a constant distance to the vortex edge for all altitudes above Sodankylä. In late December 2011 the vortex starts to be disturbed which can be seen by a change in the distance to the vortex edge. The change in the distance to the vortex edge coincides with a first short wind reversal in the mesosphere and a temper- 

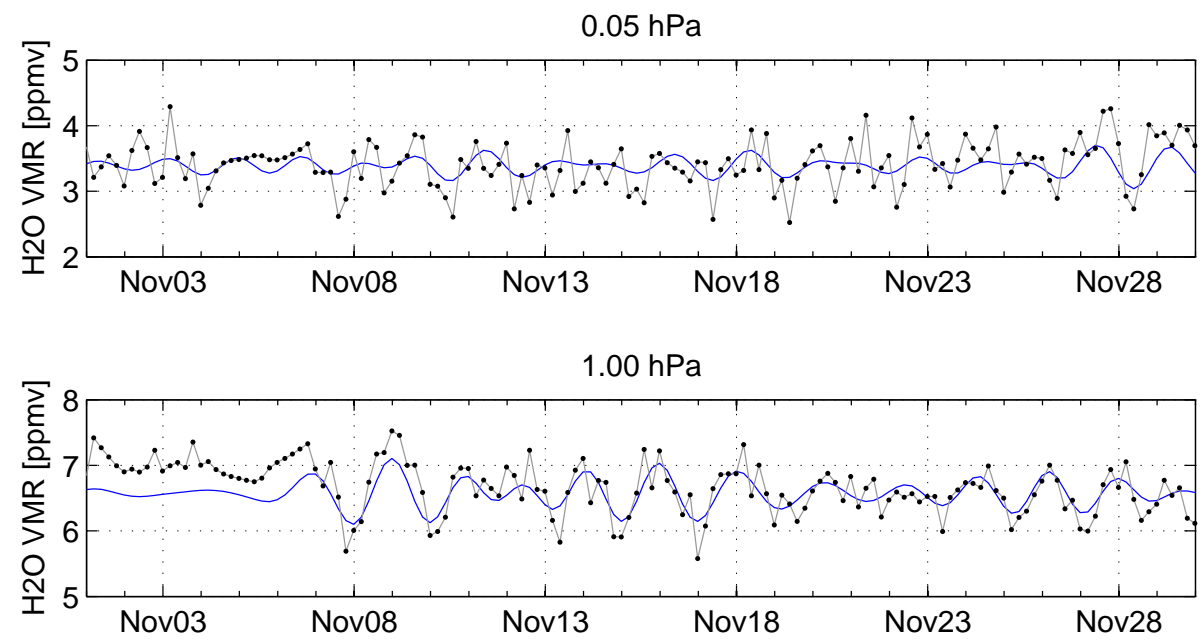

Figure 4. Measured water vapour data (black dots and grey lines) and filtered Q2DW signal (blue lines) for 0.05 and $1 \mathrm{hPa}$ for November 2011. The mean value over the time period has been added to the filtered signal and contributions with periods of 5,10 and 16 days have been subtracted from the measurement. In winter, the Q2DW is strong at $1 \mathrm{hPa}$ and accounts for most observed variations with periods shorter than 5 days.
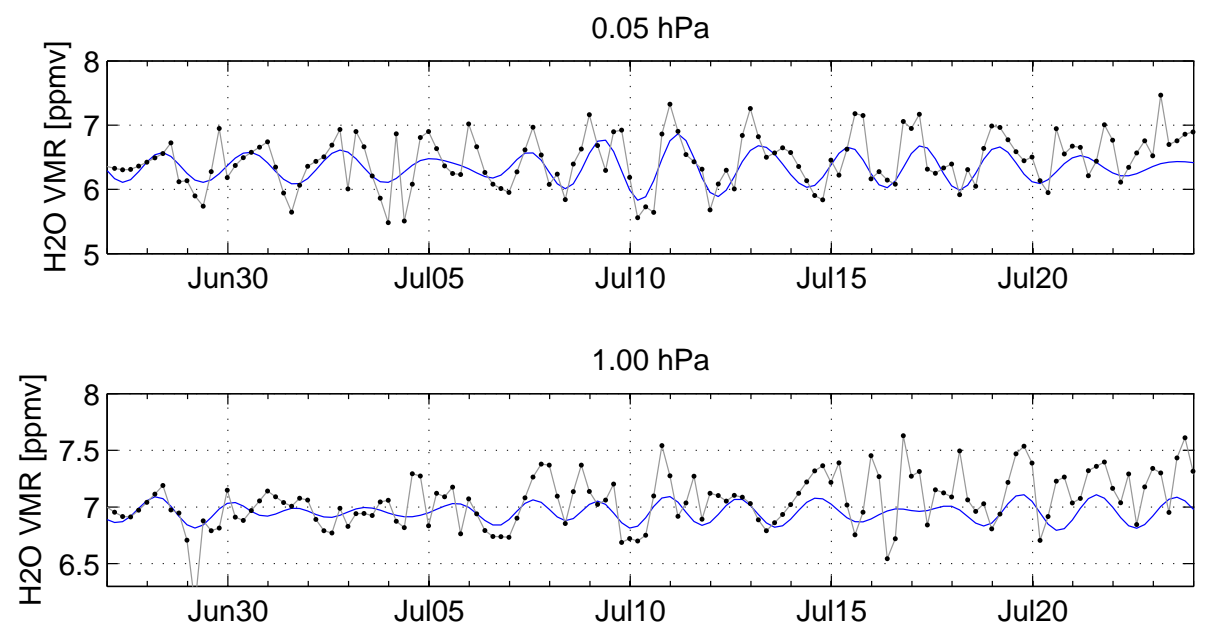

Figure 5. Measured water vapour data (black dots and grey lines) and filtered Q2DW signal (blue lines) for 0.05 and 1 hPa for July 2012. The mean value over the time period has been added to the filtered signal and contributions with periods of 5, 10 and 16 days have been subtracted from the measurement. In summer, the Q2DW is strong at $0.05 \mathrm{hPa}$ but cannot explain the observed variations with periods shorter than 5 days on $1 \mathrm{hPa}$.

ature increase and decrease in the stratosphere and mesosphere respectively (Fig. 6). In the course of the SSW midto low-latitudinal air enters the polar region as the vortex is disturbed. The air above Sodankylä is of low latitude origin which can be seen as an increase in water vapour. The period after the SSW generally shows a recovery to winter conditions, on all altitudes above Sodankylä air of the reforming polar vortex and the steady descent of the humid air is observed. For 2012 the descent is interrupted in late February. There is non-vortex air above Sodankylä resulting in a short increase of water vapour from 1 to $0.02 \mathrm{hPa}$. During this increase the vortex edge is located above Sodankylä.
The measured local water vapour time series shown in Figs. 6 and 7 shows for both the 2012 and the 2013 event a sharp increase in water vapour in the altitude range from 1 to $0.03 \mathrm{hPa}$. After the 2012 event the water vapour descends for 2 months and shows a similar behaviour as the 2010 SSW except for the short period when non-vortex air passes over Sodankylä. Even though the 2013 event is more pronounced in zonal mean temperature and wind, the effects on the local water vapour measurements are more complex. Coinciding with the wind reversal and the stratospheric warming, there is the increase in water vapour but the steady descent is only observed on the upper altitudes; water vapour isopleths of 


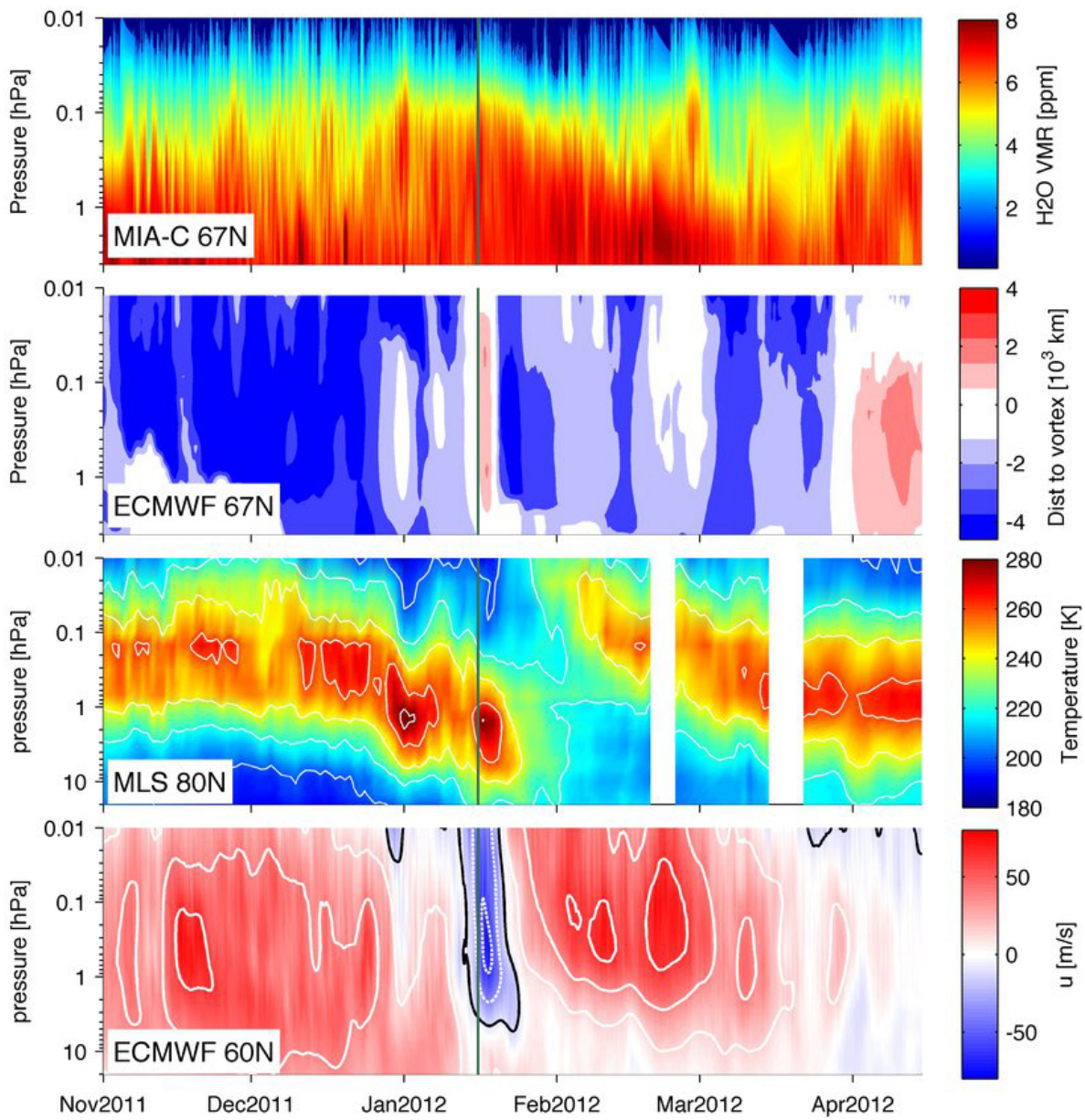

Figure 6. SSW 2012, the vertical green line marks the central date of the SSW (16 January 2012). First panel: water vapour measured by MIAWARA-C. Second panel: distance to the vortex edge (negative distance: polar vortex above Sodankylä, positive distance: non-vortex air above Sodankylä). Third panel: zonal mean temperature at $80^{\circ} \mathrm{N}$ from Aura MLS. Bottom: zonal mean zonal wind at $60^{\circ} \mathrm{N}$ from ECMWF operational analyses.

values smaller than 5 ppmv (green and blue colour) descend continuously whereas the 5-6 ppmv isopleths (orange and red colour) show a sharp and short descent right after the central date of the SSW. This descent can be explained by former vortex air passing over Sodankylä after the central date and is consistent with a double peak structure in the distance to the vortex edge.

MIAWARA-C has observed three warmings at Sodankylä. After the warmings normal polar winter conditions are reforming and the humid air which has entered in the course of the event is descending with the mean residual circulation. Following Straub et al. (2012), the descent rate of the air above Sodankylä after the SSWs is determined by linearly fitting the $5.2 \mathrm{ppmv}$ isopleth. For 2012 the time period from 16 January to 18 February is considered for the fit and 9 January to 17 February for 2013. The resulting descent rates of $364 \mathrm{~m} \mathrm{~d}^{-1}$ for 2012 and $315 \mathrm{~m} \mathrm{~d}^{-1}$ for 2013 are comparable to $350 \mathrm{~m} \mathrm{~d}^{-1}$ determined for the 2010 warming (Straub et al., 2012).

\section{Conclusions}

Observational data of middle atmospheric water vapour obtained at the Arctic research station in Sodankylä have been presented. The focus has been put on discussing the water vapour time series measured by the ground-based microwave radiometer MIAWARA-C. This instrument has monitored the water vapour evolution above Sodankylä from June 2011 to March 2013 without major measurement gaps. The temporal resolution of the retrieved profiles is approximately $1 \mathrm{~h}$ for average conditions. The high temporal resolution of the data set allows the investigation of short-term variations in this key atmospheric constituent. The data set of MIAWARA-C is used to investigate variations with periods close to 2 days related to the Q2DW. A wavelet-like analysis showed a varying activity in the mesosphere with generally higher amplitudes in the Arctic summer. Additionally, there is an enhanced activity in 2-day oscillation for both 2012 and 2013 winters below $0.1 \mathrm{hPa}$ reaching a maximum value of $0.8 \mathrm{ppmv}$ in 


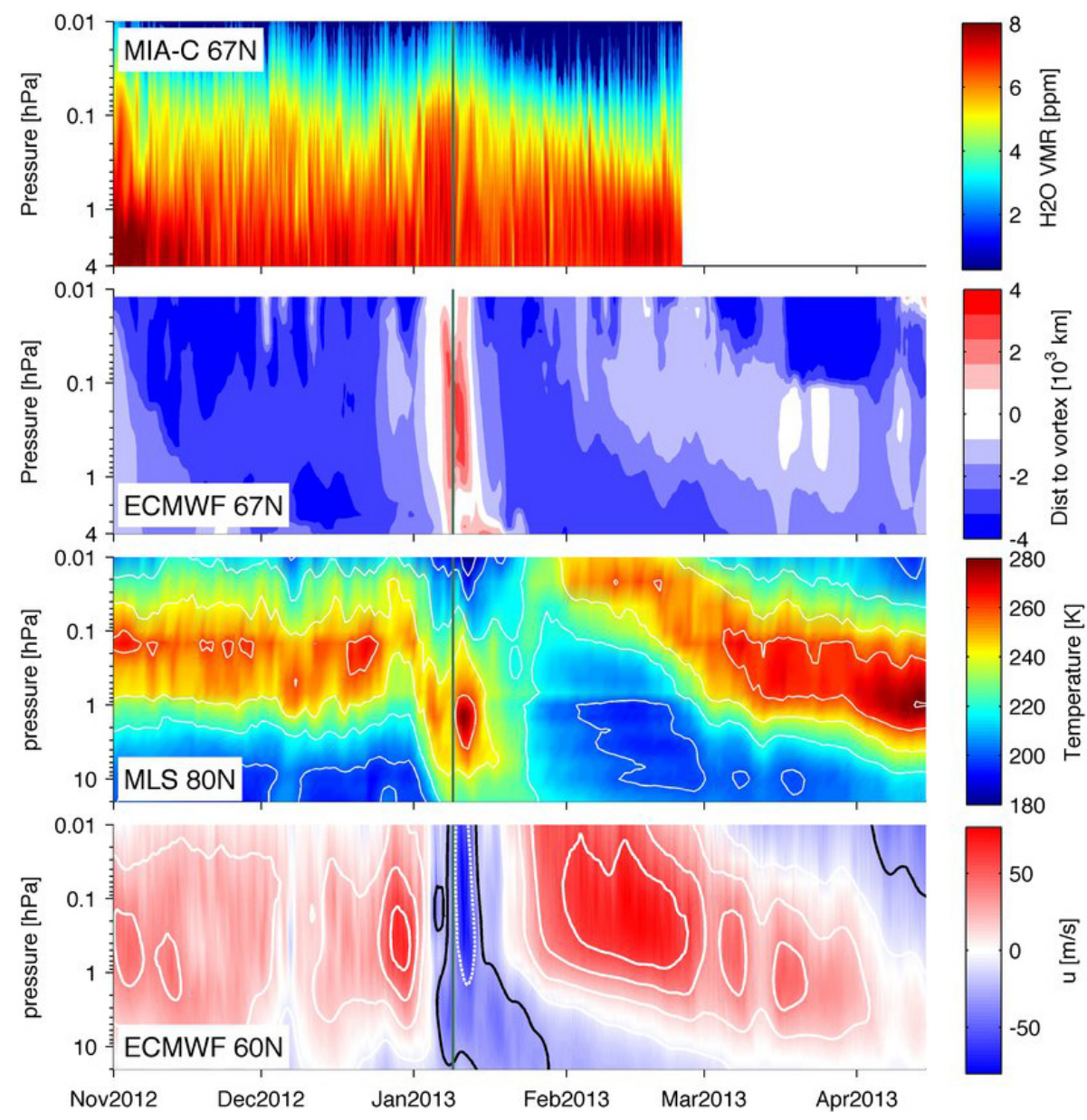

Figure 7. SSW 2013, the vertical green line marks the central date of the SSW (9 January 2013). First panel: water vapour measured by MIAWARA-C. Second panel: distance to the vortex edge (negative distance: polar vortex above Sodankylä, positive distance: non-vortex air above Sodankylä). Third panel: zonal mean temperature at $80^{\circ} \mathrm{N}$ from Aura MLS. Bottom: zonal mean zonal wind at $60^{\circ} \mathrm{N}$ from ECMWF operational analyses.

November 2011. In addition to the strong Q2DW activity, there was a SSW in both winters affecting the measured water vapour profiles. Around the zonal mean wind reversal there is a sharp increase in water vapour caused by transport of humid mid- to low-latitudinal air into polar regions from 1 to $0.06 \mathrm{hPa}$. After the SSW the circulation returns to normal winter conditions and the air descends over the Arctic region. The descent rates after the SSWs are $364 \mathrm{~m} \mathrm{~d}^{-1}$ for 2012 and $315 \mathrm{~m} \mathrm{~d}^{-1}$ for 2013; for 2010, Straub et al. (2012) found $350 \mathrm{~m} \mathrm{~d}^{-1}$. In 2012 the descent was interrupted by a short increase in water vapour in late February which can be explained by the polar air moving away from Sodankylä and the measurement of air originating from lower latitudes. Ground-based microwave radiometry of middle atmospheric water vapour thus is an excellent tool to investigate periodic structures and transport events.
Acknowledgements. This work has been supported by the Swiss National Science Foundation grant number 200020-146388. Participation at the LAPBIAT campaign was funded through the EU Sixth Framework Programme, Lapland Atmosphere-Biosphere Facility (LAPBIAT2). We thank the team of the Finnish Weather Service for their hospitality and support during the campaigns. Assistance provided by the ARTS/Qpack team is greatly appreciated. Additionally, we would like to thank $A C P$ 's production office and editorial support, the associate editor Thomas von Clarmann, and the two anonymous referees for their work.

Edited by: T. von Clarmann 


\section{References}

Brasseur, G. P., Orlando, J. J., and Tyndall, G. S. (Eds.): Atmospheric Chemistry and Global Change, Oxford University Press, 308-317, 1999.

Buehler, S. A., Eriksson, P., Kuhn, T., von Engeln, A., and Verdes, C.: ARTS, the atmospheric radiative transfer simulator, J. Quant. Spectrosc. Ra., 91, 65-93, doi:10.1016/j.jqsrt.2004.05.051, 2005.

Coy, L., Eckermann, S., and Hoppel, K.: Planetary Wave Breaking and Tropospheric Forcing as Seen in the Stratospheric Sudden Warming of 2006, J. Atmos. Sci., 66, 495-507, doi:10.1175/2008JAS2784.1, 2009.

Dörnbrack, A., Pitts, M. C., Poole, L. R., Orsolini, Y. J., Nishii, K., and Nakamura, H.: The 2009-2010 Arctic stratospheric winter general evolution, mountain waves and predictability of an operational weather forecast model, Atmos. Chem. Phys., 12, 36593675, doi:10.5194/acp-12-3659-2012, 2012.

Eriksson, P., Buehler, S. A., Davis, C., Emde, C., and Lemke, O.: ARTS, the atmospheric radiative transfer simulator, version 2, J. Quant. Spectrosc. Ra., 112, 1551-1558, doi:10.1016/j.jqsrt.2011.03.001, 2011.

Funke, B., López-Puertas, M., Bermejo-Pantaleón, D., GarcíaComas, M., Stiller, G. P., von Clarmann, T., Kiefer, M., and Linden, A.: Evidence for dynamical coupling from the lower atmosphere to the thermosphere during a major stratospheric warming, Geophys. Res. Lett., 37, L13803, doi:10.1029/2010GL043619, 2010.

Hocke, K., Studer, S., Martius, O., Scheiben, D., and Kämpfer, N.: A 20-day period standing oscillation in the northern winter stratosphere, Ann. Geophys., 31, 755-764, doi:10.5194/angeo31-755-2013, 2013.

Kämpfer, N., Nedoluha, G., Haefele, A., and Wachter, E. D.: ISSI Scientific Report Series: Microwave Radiometry, Springer, New York, 71-93, doi:10.1007/978-1-4614-3909-7, 2012.

Kulikov, M. Y.: Theoretical investigation of the influence of a quasi-2-day wave on nonlinear photochemical oscillations in the mesopause region, J. Geophys. Res.-Atmos., 112, D02305, doi:10.1029/2005JD006845, 2007.

Lee, J. N., Wu, D. L., Manney, G. L., Schwartz, M. J., Lambert, A., Livesey, N. J., Minschwaner, K. R., Pumphrey, H. C., and Read, W. G.: Aura Microwave Limb Sounder observations of the polar middle atmosphere: Dynamics and transport of $\mathrm{CO}$ and $\mathrm{H}_{2} \mathrm{O}$, J. Geophys. Res., 116, D05110, doi:10.1029/2010JD014608, 2011.

Limpasuvan, V. and $\mathrm{Wu}, \mathrm{D}$. L.: Two-day wave observations of UARS Microwave Limb Sounder mesospheric water vapor and temperature, J. Geophys. Res.-Atmos., 108, 4307, doi:10.1029/2002jd002903, 2003.

Limpasuvan, V., Leovy, C. B., and Orsolini, Y. J.: Observed Temperature Two-Day Wave and Its Relatives near the Stratopause, J. Atmos. Sci., 57, 1689-1701, doi:10.1175/15200469(2000)057<1689:OTTDWA>2.0.CO;2, 2000.

Lossow, S., Urban, J., Schmidt, H., Marsh, D. R., Gumbel, J., Eriksson, P., and Murtagh, D.: Wintertime water vapor in the polar upper mesosphere and lower thermosphere: First satellite observations by Odin submillimeter radiometer, J. Geophys. Res., 114, 1196, doi:10.1029/2008JD011462, 2009.

Manney, G. L., Schwartz, M., Krueger, K., Santee, M., Pawson, S., Lee, J., Daffer, W., Fuller, R., and Livesey, N.: Aura Microwave Limb Sounder Observations of Dynamics and Trans- port During the Record-breaking 2009 Arctic Stratospheric Major Warming, Geophys. Res. Lett., 36, L12815, D10304, doi:10.1029/2009GL038586, 2009.

Merkel, A. W., Thomas, G. E., Palo, S. E., and Bailey, S. M.: Observations of the 5-day planetary wave in PMC measurements from the Student Nitric Oxide Explorer Satellite, Geophys. Res. Lett., 30, 1196, doi:10.1029/2002GL016524, 2003.

Merkel, A. W., Rusch, D. W., Palo, S. E., Russell III, J. M., and Bailey, S. M.: Mesospheric planetary wave effects on global PMC variability inferred from AIM-CIPS and TIMED-SABER for the northern summer 2007 PMC season, J. Atmos. Sol.-Terr. Phy., 71, 381-391, doi:10.1016/j.jastp.2008.12.001, 2009.

Nassar, R., Bernath, P. F., Boone, C. D., Manney, G. L., McLeod, S. D., Rinsland, C. P., Skelton, R., and Walker, K. A.: ACE-FTS measurements across the edge of the winter 2004 Arctic vortex, Geophys. Res. Lett., 32, L15S05, n/a-n/a, doi:10.1029/2005GL022671, 2005.

Nozawa, S., Iwahashi, H., Brekke, A., Hall, C., Manson, C. M. A., Oyama, S., Murayama, Y., and Fujii, R.: The quais 2-day wave observed in the polar mesosphere: Comparison of the characteristics observed at Tromso and Poker Flat, J. Geophys. Res.Atmos., 108, 4748, doi:10.1029/2002jd003221, 2003.

Pedatella, N. M., Fuller-Rowell, T., Wang, H., Jin, H., Miyoshi, Y., Fujiwara, H., Shinagawa, H., Liu, H.-L., Sassi, F., Schmidt, H., Matthias, V., and Goncharenko, L.: The neutral dynamics during the 2009 sudden stratosphere warming simulated by different whole atmosphere models, J. Geophys. Res., 119, 1306-1324, doi:10.1002/2013JA019421, 2014.

Rodgers, C. D.: Inverse Methodes for Atmospheric Soundings, World Scientific Publishing Co. Pte. Ltd, Singapore, 2000.

Salmi, S.-M., Verronen, P. T., Thölix, L., Kyrölä, E., Backman, L., Karpechko, A. Yu., and Seppälä, A.: Mesosphere-to-stratosphere descent of odd nitrogen in February-March 2009 after sudden stratospheric warming, Atmos. Chem. Phys., 11, 4645-4655, doi:10.5194/acp-11-4645-2011, 2011.

Sandford, D. J., Schwartz, M. J., and Mitchell, N. J.: The wintertime two-day wave in the polar stratosphere, mesosphere and lower thermosphere, Atmos. Chem. Phys., 8, 749-755, doi:10.5194/acp-8-749-2008, 2008.

Scheiben, D., Straub, C., Hocke, K., Forkman, P., and Kämpfer, N.: Observations of middle atmospheric $\mathrm{H}_{2} \mathrm{O}$ and $\mathrm{O}_{3}$ during the 2010 major sudden stratospheric warming by a network of microwave radiometers, Atmos. Chem. Phys., 12, 7753-7765, doi:10.5194/acp-12-7753-2012, 2012.

Scheiben, D., Tschanz, B., Hocke, K., Kämpfer, N., Ka, S., and Oh, J. J.: The quasi 16-day wave in mesospheric water vapor during boreal winter 2011/2012, Atmos. Chem. Phys., 14, 6511-6522, doi:10.5194/acp-14-6511-2014, 2014.

Sonnemann, G. R., Hartogh, P., Grygalashvyly, M., Li, S., and Berger, U.: The quasi 5-day signal in the mesospheric water vapor concentration at high latitudes in 2003 - a comparison between observations at ALOMAR and calculations, J. Geophys. Res.-Atmos., 113, D04101, doi:10.1029/2007JD008875, 2008.

Straub, C., Murk, A., and Kämpfer, N.: MIAWARA-C, a new ground based water vapor radiometer for measurement campaigns, Atmos. Meas. Tech., 3, 1271-1285, doi:10.5194/amt-31271-2010, 2010.

Straub, C., Tschanz, B., Hocke, K., Kämpfer, N., and Smith, A. K.: Transport of mesospheric $\mathrm{H}_{2} \mathrm{O}$ during and after the stratospheric 
sudden warming of January 2010: observation and simulation, Atmos. Chem. Phys., 12, 5413-5427, doi:10.5194/acp-12-54132012, 2012.

Studer, S., Hocke, K., and Kämpfer, N.: Intraseasonal Oscillations of Stratospheric Ozone Above Switzerland, J. Atmos. Sol.-Terr. Phy., 74, 189-198, doi:10.1016/j.jastp.2011.10.020, 2012.

Tschanz, B., Straub, C., Scheiben, D., Walker, K. A., Stiller, G. P., and Kämpfer, N.: Validation of middle-atmospheric campaignbased water vapour measured by the ground-based microwave radiometer MIAWARA-C, Atmos. Meas. Tech., 6, 1725-1745, doi:10.5194/amt-6-1725-2013, 2013.

Tunbridge, V. M. and Mitchell, N. J.: The two-day wave in the Antarctic and Arctic mesosphere and lower thermosphere, Atmos. Chem. Phys., 9, 6377-6388, doi:10.5194/acp-9-6377-2009, 2009.
Tunbridge, V. M., Sandford, D. J., and Mitchell, N. J.: Zonal wave numbers of the summertime 2 day planetary wave observed in the mesosphere by EOS Aura Microwave Limb Sounder, J. Geophys. Res., 116, D11103, doi:10.1029/2010JD014567, 2011.

Wu, D. L., Hays, P. B., Skinner, W. R., Marshall, A. R., Burrage, M. D., Lieberman, R. S., and Ortland, D. A.: Observations of the Quasi 2-Day Wave from the High-Resolution Doppler Imager on Uars, Geophys. Res. Lett., 20, 2853-2856, doi:10.1029/93GL03008, 1993. 